Department of Pharmacology,

Faculty of Veterinary Medicine,

Suez Canal University.

\title{
ANTINOCICIPTIVE EFFECT OF GINGER EXTRACT IN STREPTOZOTOCIN-INDUCED DIABETIC RATS
}

(With 3 Figures)

\author{
By \\ M. ABDEL DAIM \\ (Received at 12/12/2011) \\ التأثير المسكن للآلام لخلاصة الزنجبيل في الفئران المصابة بالسكري المحدث \\ بالاستريتوزوتوسين$$
\text { محد عبد الدايم }
$$

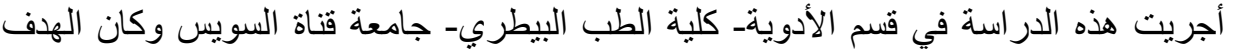

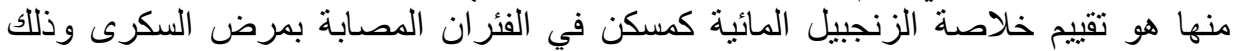

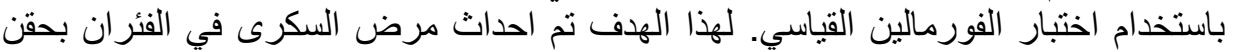

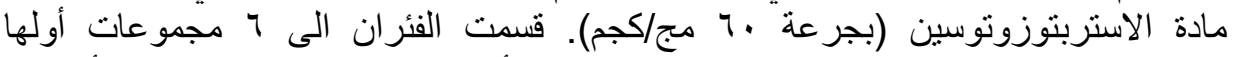

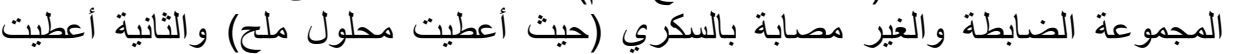



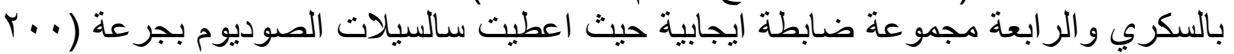

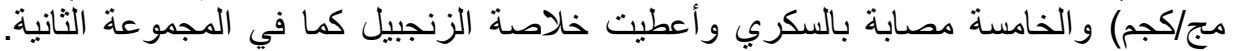

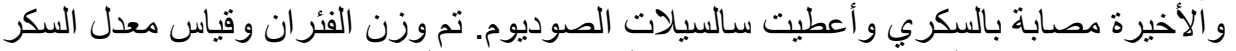

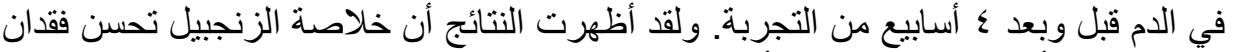

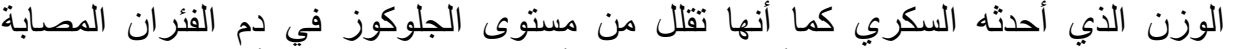

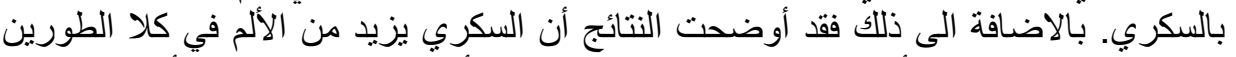

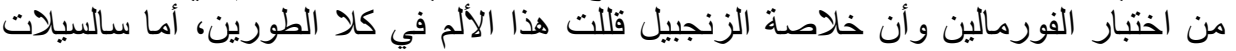

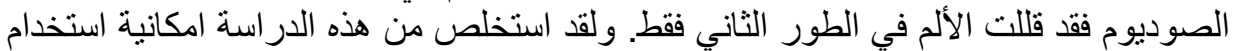 \\ خلاصة الزنجبيل كمسكن للألام في مرضنى السكري.
}

\section{SUMMARY}

Hyperalgesia is one of the major symptoms of diabetic neuropathy in diabetic patients. Streptozotocin (STZ)-induced diabetic rats display exaggerated hyperalgesic behavior in response to noxious stimuli, and the most commonly employed animal model aspect of painful diabetic 
neuropathy. This study was designed to evaluate the analgesic effect of oral Ginger extract on formalin-induced nociceptive responses (standard formalin test) in STZ-induced diabetic rats. For this purpose, STZdiabetic rats were orally given the aqueous extract of Ginger roots in a dose of $200 \mathrm{mg} \mathrm{kg}^{-1} /$ day for one month. The results showed that there was an increase in the pain scores in both phases of the test in the diabetic group. It was found out that treatment with Ginger extract significantly reduced blood glucose in diabetic rats and Ginger-treated diabetic rats exhibited a lower pain score for both phases of the test as compared to untreated-diabetic ones. In contrast, sodium salicylate which acts as positive control only reduced pain scores in the second phase. It could be concluded that oral intake of Ginger extract for one month has a therapeutic potential for treating painful diabetic neuropathy.

Key words: Diabetes mellitus, ginger extract, streptozotocin, rats.

\section{INTRODUCTION}

Diabetes mellitus (DM), one of the major metabolic disorders, is characterized by high blood glucose levels due to the inability of body cells to utilize glucose properly. Diabetes is recognized for severe complications such as diabetic nephropathy, neuropathy, and retinopathy (Rohrbach and Martin, 1982) (Shimomura and Spiro, 1987). Streptozotocin (STZ), a glucosamine-nitrosourea compound has a chemical name of 2-deoxy-2-(3-methyl-3-nitrosoureido)-Dglucopyranose (C8H15N3O7). Streptozotocin has been used as a diabetogenic agent in experimental animals. The mechanisms of STZinduced diabetes are considered as follows: first, STZ causes DNA strand break in pancreatic islet and stimulates nuclear poly (ADP-ripose) synthetase and thus depletes the intracellular NAD+ and NADP+ levels, which inhibit proinsulin synthesis and induce diabetes (Wilson et al., 1988). Second, Activated oxygen species, such as superoxide, hydrogen peroxide, hydroxyl radical and singlet oxygen, have been implicated to play a role in diabetes (Sato et al., 1979). Streptozotocin-induced diabetes in the rat has been increasingly used as a model of painful diabetic neuropathy to assess the efficacies of potential analgesic agents (Forman et al., 1986). It has been well known that diabetic rats display exaggerated hyperalgesic behavior in response to noxious stimuli like paw formalin injection that may resemble and model aspects of painful 
diabetic neuropathy (Freshwater et al., 2002). This enhanced nociception has been observed in the early stages of diabetic neuropathy in STZdiabetic rats (Rutledge et al., 2002). Despite great achievements in analgesic drugs development, there is still a need for new analgesics devoid of the side effects presented by opioids or non-steroidal antiinflammatory drugs for the treatment of some acute and chronic pain conditions (Rutledge et al., 2002). Among various forms of treatments for DM, diet is of vital importance. Foods of medicinal value have been proved effective and thus are widely used as they combine two basic central factors: food and medication (Oubre et al., 1997) (Grower et al., 2002). Ginger (Zingiber officinale Roscoe, Zingiberacae) is widely used around the world in foods as a spice. For centuries, it has been an important for the treatment of catarrh, rheumatism, nervous diseases, gingivitis, toothache, asthma, stroke, constipation and diabetes (Awang 1992; Wang and Wang 2005; Tapsell et al., 2006). In Egypt, Ginger has been known as a medicinal plant with a traditional use in diabetes. Beneficial effects of this medicinal plant have been demonstrated in diabetic animals and both insulin-dependent and non-insulin-dependent diabetic subjects (Al-Amin et al., 2006). The results of previous studies have demonstrated that aqueous extract of ginger given both orally and intraperitoneally possesses a hypoglycaemic effect in normoglycaemic and alloxan induced hyperglycaemic rats (Shalaby and Hamowieh, 2010). On the other hand, anti-inflammatory, antipyretic and analgesic effects of this extract have been previously reported in normal rats and mice (Afzal et al., 2001). Although the use of herbal and natural supplements in some countries has increased dramatically in recent years, but claims of their therapeutic effects abound, medical research has not always supported their effectiveness. Therefore, this study was carried out to evaluate the antinociceptive effect of aqueous ginger extract in STZ-induced diabetic rats using standard formalin test.

\section{MATERIALS and METHODS}

\section{Materials:}

Ginger; powder of dried roots of Zingiber officinale was kindly given by Arab Company for Pharmaceuticals and Medicinal Plants (MEPACO) - Egypt, dissolved in water in the form of aqueous ginger extract and the oral dose used is $200 \mathrm{mg} / \mathrm{kg}$ according to (Bhandari et al., 2005). Streptozotocin (STZ, $60 \mathrm{mg} / \mathrm{Kg}$; Sigma chemical company, St Louis, Missouri. USA.) 


\section{Animals:}

Mature male albino rats weighing 175-225 g, purchased from the animal house of National Research Centre, were used and provided with standard laboratory diet and water ad libitum. Sixty rats were randomly divided into six experimental groups each of 10 as following; $1^{\text {st }}$ control non-diabetic group receiving $0.9 \%$ saline, $2^{\text {nd }}$ Ginger root aqueous extract-treated non-diabetic control group. $3^{\text {rd }}$ Sodium salicylate-treated rats used as a positive non-diabetic control group, $4^{\text {th }}$ vehicle-treated diabetic group, $5^{\text {th }}$ Ginger root aqueous extract treated-diabetic group and $6^{\text {th }}$ Sodium salicylate-treated- diabetic rats used as a diabetic positive control group. All procedures involving animals were performed in accordance with the guidelines for the use and care of laboratory animals which approved by the Departmental Committee on the use and care of laboratory animals, National Research Center, Dokki, Egypt.

\section{Induction of diabetes:}

Thirty rats were kept on fasting prior to streptozotocin injection. On the day of administration, STZ was freshly dissolved in $50 \mathrm{mM}$ sodium citrate $(\mathrm{pH} 4.5)$ solution containing $150 \mathrm{mM} \mathrm{NaCl}$ and subcutaneous injection was given at the dosage of $60 \mathrm{mg} / \mathrm{kg}$ bw. Blood glucose concentration was measured by electronic glucometer. After 3 days of STZ injection, the animals with glucose concentration exceeding $250 \mathrm{mg} / \mathrm{dl}$ were considered diabetic (Abdulrazaq et al., 2011).

\section{Study design:}

Ginger extract was given orally using a stomach tube at a dose of $200 \mathrm{mg} / \mathrm{kg}$ for one month beginning from day 3 after streptozotocin administration for the 2 nd and 5 th groups. Sodium salicylate was given orally for the 3rd and 6th groups at a dose of $200 \mathrm{mg} / \mathrm{kg} 60$ minutes before the formalin test. Body weight and serum blood glucose levels for all rats were monitored at the beginning and the end of the experiment. The rats were fasted for eight hours, and blood samples were collected by tail nipping and assessed for blood glucose by an electronic glucometer.

\section{Formalin Test:}

For assessment of pain, formalin test was used according to the previously described method (Dubuisson and Dennis, 1977). Briefly, each animal was acclimatized to the observation box before any testing began. Then, it was given a subcutaneous injection 50 ul of $2.5 \%$ formalin in the planter surface of right hand paw using 25 -gauge syringe needle. Each rat was then immediately placed in a Plexiglas box. 
Observations to determine nociceptive responses began upon placing the rat into the box and continued for the next $60 \mathrm{~min}$. A nociceptive score (Coderre et al., 1993) was determined for each 5 min block during that period by measuring the amount of time spent in each of the four behavioral categories: 0 , the position and posture of the injected hind paw is indistinguishable from the contralateral paw; 1 , the injected paw has little or no weight placed on it; 2 , the injected paw is elevated and is not in contact with any surface; 3 , the injected paw is licked, bitten, or shaken. Then, a weighted nociceptive score, ranging from 0 to 3 was calculated by multiplying the time spent in each category by the category weight, summing these products and dividing by the total time for each 5 min block of time. The first 10 min post-formalin was considered as the early phase, and the time interval $15-60$ as the late phase.

\section{Data and Statistical Analysis:}

All values were given as mean \pm S.E.M. Statistical analysis was carried out using student's paired t-test and one-way analysis of variance (ANOVA) according to Snedecor and Cochran (1989) using SPSS Version, 16. For Means separation, Duncan's Multiple Range Test, (1955) was used. Probability level at $\mathrm{P} \leq 0.01$ is highly Significant.

\section{RESULTS}

Body weight and serum glucose level were measured before and at $4^{\text {th }}$ week of the experiment (Fig. $1 \& 2$ ). At the beginning of experiment, there were no significant differences among groups. At the end of 4 weeks, the body weight of the untreated and Ginger-treated diabetic $(\mathrm{P}<0.01)$ rats was found to be significantly lower as compared to control rats. It was of interest that although weight of Ginger-treated diabetic rats was $4.8 \%$ greater than untreated-diabetic, but the existing difference was insignificant. In addition, untreated- and Ginger-treated diabetic rats also had elevated blood glucose level over those of control rats $(\mathrm{P}<0.001)$. In this respect, treatment of diabetic rats with Ginger extract caused a significant reduction in the latter parameter in comparison with untreated-diabetic ones $(\mathrm{P}<0.01)$. On the other hand, although the blood glucose level of ginger extract treated control was about 3\% lower than untreated control animals, but the existing deference was insignificant. Formalin produced a marked biphasic response in rats of all groups. Formalin-induced hyperalgesia was significantly $(\mathrm{P}<0.01)$ more marked in untreated-diabetic than in control rats in both phases of the formalin test (Fig. 3). Treatment of rats with 
oral sodium salicylate $(200 \mathrm{mg} / \mathrm{Kg})$ caused a significant reduction $(\mathrm{P}<0.01)$ in nociceptive score only in the second phase of the formalin test as compared to control rats (Fig. 3). In contrast, treatment of nondiabetic rats with Ginger extract $(200 \mathrm{mg} / \mathrm{Kg})$ caused lower nociceptive scores in both phases of the formalin test $(\mathrm{P}<0.05)$ in comparison with untreated control ones (Fig. 3). Furthermore, diabetic animals receiving Ginger extract showed a less intensive nociceptive behavior as compared to untreated diabetic rats (Fig. 3).

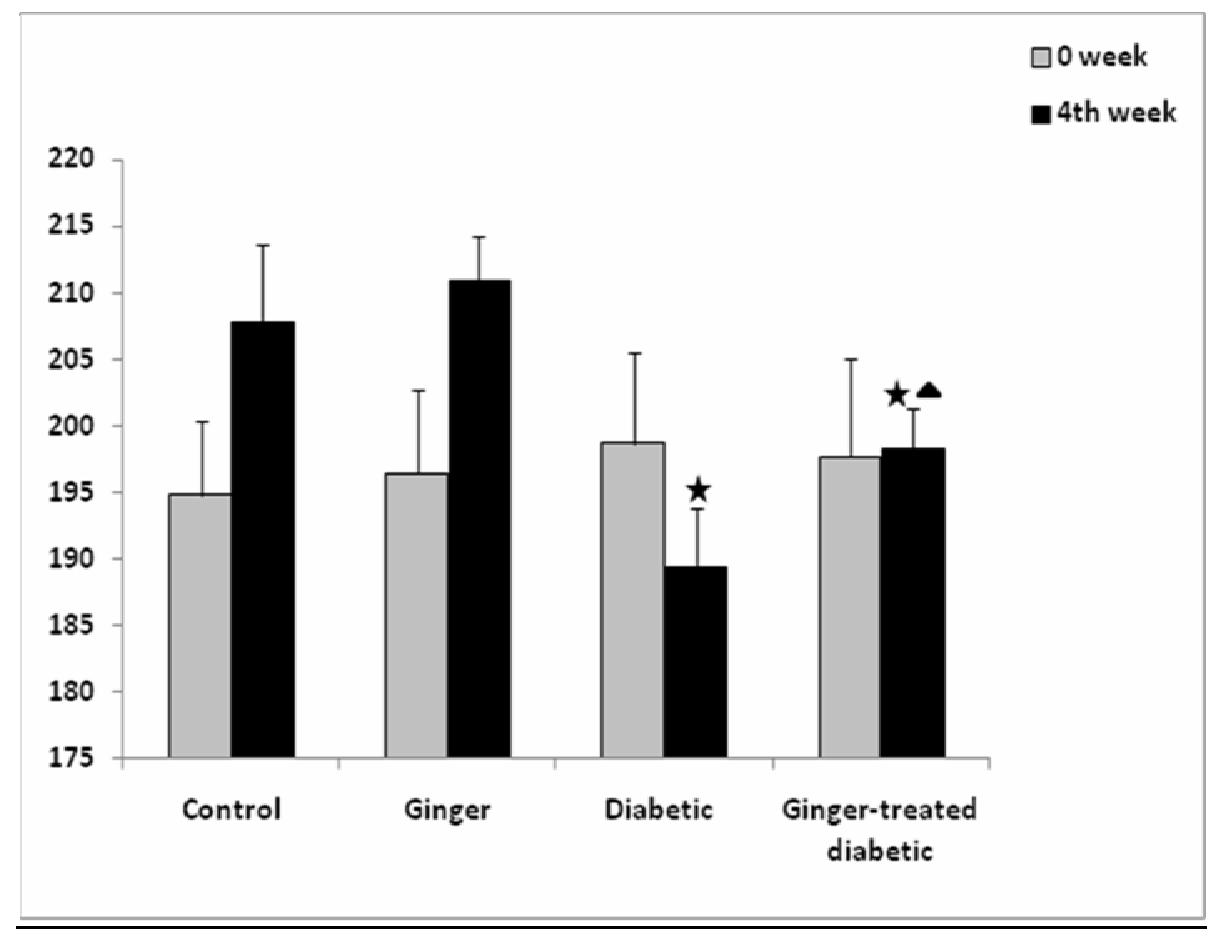

Fig. 1: The effect of oral aqueous ginger extract $200 \mathrm{mg} \mathrm{kg}^{-1} /$ day for one month) on the body weight of STZ-induced diabetic rats. All data explained as Mean \pm S.E.M.

$\star \mathrm{P}<0.01$ (as compared to non-diabetic control) $\quad \boldsymbol{\Delta}<0.01$ (as compared to diabetic control) 


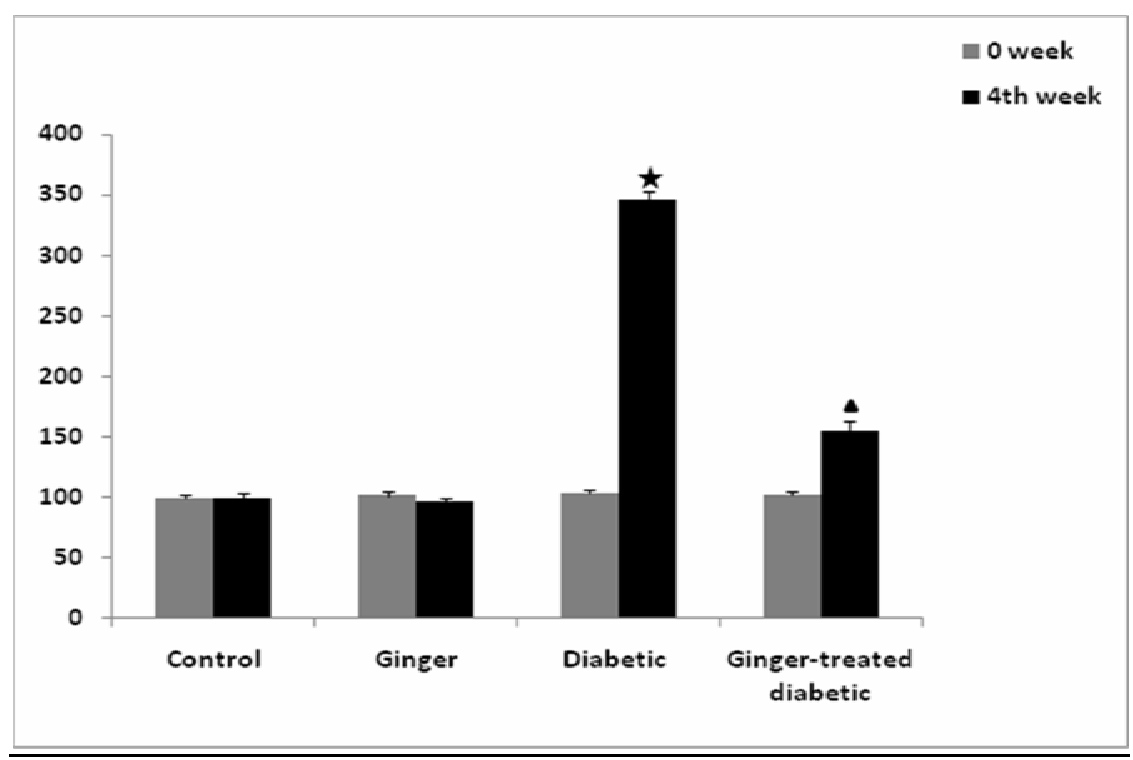

Fig. 2: The effect of oral aqueous ginger extract $\left(200 \mathrm{mg} \mathrm{kg}^{-1} /\right.$ day for one month) on blood glucose level in STZ-induced diabetic rats. All data explained as Mean \pm S.E.M.

$\star \mathrm{P}<0.01$ (as compared to non-diabetic control) $\boldsymbol{\Delta} \mathrm{P}<0.01$ (as compared to diabetic control)

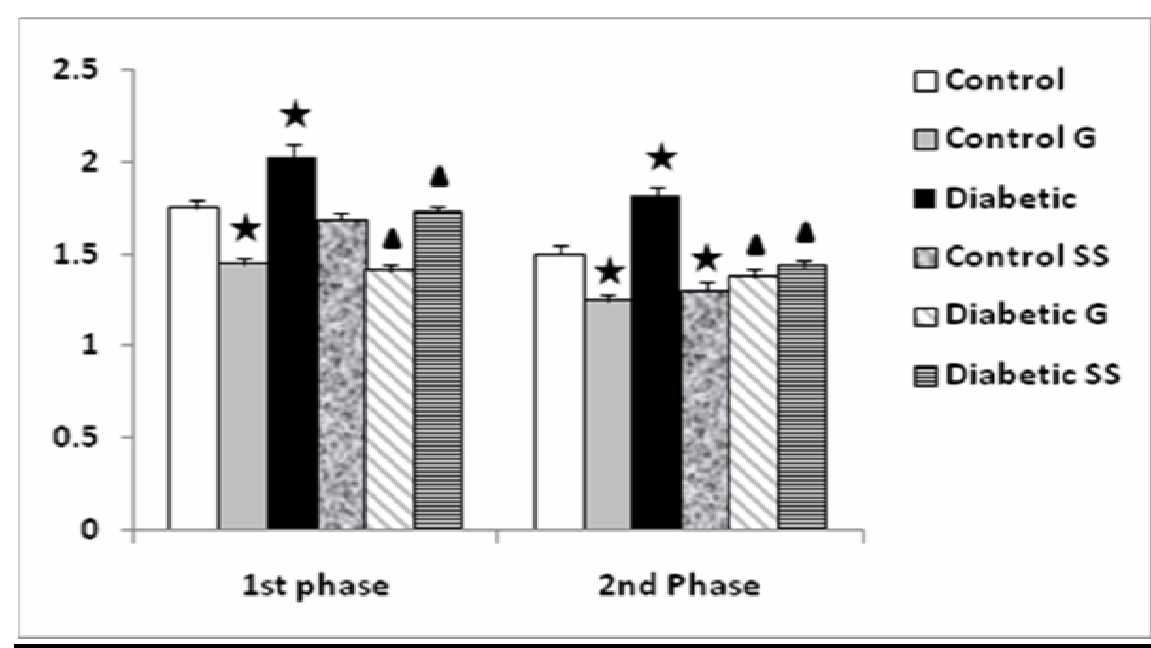

Fig. 3: The effect of oral aqueous ginger extract $\left(200 \mathrm{mg} \mathrm{kg}^{-1} /\right.$ day for one month) and sodium salicylate (SS, $200 \mathrm{mg} / \mathrm{Kg}$ ) on nociceptive scores in $1^{\text {st }}$ (early) and $2^{\text {nd }}$ (late) phases of formalin test. All data explained as Mean \pm S.E.M.

$\star \mathrm{P}<0.01$ (as compared to non-diabetic control) $\quad \Delta \mathrm{P}<0.01$ (as compared to diabetic control) 


\section{DISCUSSION}

In this study, the possible antinociceptive effect of Zingiber officinale aqueous extract in STZ-induced diabetic rats using formalin test was investigated. There are two main conclusions to be drawn from the obtained results as follows: First, the results clearly demonstrated that there is an intensified nociceptive response in both phases of the formalin test in diabetic rats. It is a well-established fact that diabetic rats display exaggerated hyperalgesic behavior in response to noxious stimuli that may model aspects of painful diabetic neuropathy (Dobretsov et al., 2001) and for this reason STZ-induced diabetic rats have been increasingly used as a model of painful diabetic neuropathy to assess the efficacies of potential analgesic agents (Freshwater et al., 2002). Although evaluation of mechanisms causing these symptoms is complicated because of the overlap between the systemic effects of hyperglycemia and its toxic effects within the peripheral nervous system, but direct functional toxicity of hyperglycemia in the peripheral nervous system (Freshwater et al., 2002), an increased activity of primary afferent fibres leading to an increased excitatory tone within the spinal cord, increased release of glutamate and activation of the N-Methyl-Daspartate (NMDA) receptor, reduced activity of both opioidergic and gamma-Aminobutyric acid (GABA) inhibitory systems, decreased activity of neuronal nitric oxide synthase-cyclic guanosine monophosphate (nNOS-cGMP) system in neurons of dorsal root ganglion, altered sensitivity of the dopaminergic receptors and altered responsiveness of the dopaminergic system, possibly through the enhancement and/or deactivation of the endogenous Metenkephalinergic system, alterations in L-type $\mathrm{Ca} 2+$ channels and some changes in central and peripheral endogenous opiate levels could be involved in the modulation of nociception in diabetic rats (Fox et al., 1999).

Secondly, it was demonstrated that oral administration of aqueous Zingiber officinale root extract at a dose of $200 \mathrm{mg} / \mathrm{Kg}$ for a period of one month could produce a significant antinociceptive effect in both phases of the formalin test in control and diabetic rats. On the other hand, sodium salicylate significantly reduced the nociceptive score only in the second phase of the formalin test. The previous studies have strongly indicated that administration of the ginger extract possess antiinflammatory, antipyretic and anti-nociceptive effects (Afzal et al., 2001). It has been known that centrally-acting drugs like narcotics inhibit both phases of the formalin test equally, while peripheral acting 
drugs like aspirin only inhibit the late phase). Therefore, the effect of sodium salicylate in this study has been mediated through a peripheral mechanism, while the effect of ginger extract could be mediated through a central and possibly, via a peripheral mechanism. One of the possible mechanisms which could partially explain the beneficial analgesic effect of ginger in this study may be attributed to its hypoglycemic (Amin et al., 2006; Fox et al., 1999) and antioxidant (Madkor et al., 2011) effects. Since hyperglycemia in diabetic state could induce some functional alterations in the nervous system, ginger extract through lowering blood glucose could attenuate the hyperalgesia, as has been observed in the present study. In agreement with our data obtained from diabetic rats, it has been demonstrated that the aqueous extract of ginger possesses a hypoglycaemic effect in streptozotocin-nicotinamide induced hyperglycaemic rats (Madkor, 2011). On the other hand, since oxidative stress play a key role in the complications of diabetes, therefore, ginger administration to diabetic animals could cause partial reversal of the disturbed antioxidant levels and peroxidative damage (Madkor, 2011; Jagetia et al., 2003; Yemitan 2006). To conclude, the data reported herein confirm that diabetes-induced hyperalgesia is attenuated following oral administration of Zingiber officinale root extract as determined by formalin test and this may be of potential benefit in painful diabetic neuropathy.

\section{ACKNOWLEDGEMENTS}

The author acknowledges Arab Company for Pharmaceuticals and Medicinal Plants (MEPACO) - Egypt, for providing the aqueous ginger extract used in this study.

\section{REFERENCES}

Abdulrazaq, NB.; Cho, MM.; Win, NN.; Zaman, R. and Rahman, MT. (2011): Beneficial effects of ginger (Zingiber officinale) on carbohydrate metabolism in streptozotocin-induced diabetic rats. Br J. Nutr. Dec. 12:1-8.

Afzal, M.; Al-Hadidi, D.; Menon, M.; Pesek, J. and Dhami, M.S. (2001): Ginger: an ethnomedical, chemical and pharmacological review. Drug Metab. Drug Interact. 18: 159-190.

Al-Amin, ZM.; Thomson, M.; Al-Qattan, KK.; Peltonen-Shalaby, R. and Ali, M. (2006): Anti-diabetic and hypolipidaemic properties of ginger (Zingiber officinale) in streptozotocin-induced diabetic 
rats. Br. J. Nutr. 96(4): 660-6.

Argyrous, G. Statistics or Research: With a Guide to SPSS, SAGE, London, and ISBN 1412919487

Awang, D.V.C. (1992): Ginger. Can. Pharm. J. 125: 309-311.

Bhandari, U.; Kanojia, R. and Pillai, KK. (2005): Effect of ethanolic extract of Zingiber officinale on dyslipidaemia in diabetic rats.J Ethnopharmacol. 28, 97(2): 227-30.

Coderre, TJ.; Fundytus, ME.; McKenna, JE.; Dalal, S. and Melzack, R. (1993): The formalin test: a validation of the weighted-scores method of behavioural pain rating. Pain. 54(1): 43-50.

Dobretsov, M.; Hastings, SL.; Stimers, JR. and Zhang, JM. (2001): Mechanical hyperalgesia in rats with chronic perfusion of lumbar dorsal root ganglion with hyperglycemic solution. J Neurosci Methods, 110:9-15.

Dubuisson, D. and Dennis, SG. (1977): The formalin test: a quantitative study of the analgesic effects of morphine, meperidine, and brain stem stimulation in rats and cats. Pain. 4(2): 161-74.

Duncan, D.B. (1955): Multiple range and multiple F tests, Biometrics, $11,1-42$.

Forman, LJ.; Estilow, S.; Lewis, M. and Vasilenko, P. (1986): Streptozocin diabetes alters immunoreactive beta-endorphin levels and pain perception after $8 \mathrm{wk}$ in female rats. Diabetes 35: 1309-1313.

Fox, A.; Eastwood, C.; Gentry, C.; Manning, D. and Urban, L. (1999): Critical evaluation of the streptozotocin model of painful diabetic neuropathy in the rat. Pain, 81: 307-316.

Freshwater, JD.; Svensson, CI.; Malmberg, AB. and Calcutt, NA. (2002): Elevated spinal cyclooxygenase and prostaglandin release during hyperalgesia in diabetic rats. Diabetes 51: 22492255.

Grower, JK.; Yadav, S. and Vats, V. (2002): Medicinal plants of India with anti-diabetic potential. J Ethnopharmacol, 81: 81-100.

Jagetia, G.C.; Baliga, M.S.; Venkatesh, P. and Ulloor, J.N. (2003): Influence of ginger rhizome (Zingiber officinale Rosc.) on survival, glutathione and lipid peroxidation in mice after whole-body exposure to gamma radiation. Radiat. Res. 160: 584-592.

Madkor, HR.; Mansour, SW. and Ramadan, G. (2010): Modulatory effects of garlic, ginger, turmeric and their mixture on hyperglycaemia, dyslipidaemia and oxidative stress in 
streptozotocin-nicotinamide diabetic rats. Br J. Nutr. 2011 Apr; 105 (8):1210-7. Epub, 10.

Oubre, AY.; Carlson, TJ.; Kiny, SR. and Reaven, GM. (1997): From plant to patient-ban ethnomedical approach to the identification of new drugs to the treatment of NIDDM. Diabetologia, 40: 614-617.

Rohrbach, DH. and Martin, GR. (1982): Structure of basement membrane in normal and diabetic tissues. Ann. N. YAcad Sci. 401: 203-211.

Rutledge, LP.; Ngong, JM.; Kuperberg, JM.; Samaan, SS.; Soliman, KF. and Kolta, MG. (2002): Dopaminergic system modulation of nociceptive response in long-term diabetic rats. Pharmacol Biochem Behav 74: 1-9.

Sato, Y. and Hotta, N. (1979): Sakamoto N, Matsuoka S, Ohishi N, Yagi K.Lipid peroxide level in plasma of diabetic patients. Biochem Med., 21(1): 104-7.

Shalaby, M.A. and Hamowieh, A.R. (2010): Safety and efficacy of Zingiber officinale roots on fertility of male diabetic rats. Food and Chemical Toxicology, 48 (10): 2920-2924

Shimomura, H. and Spiro, RG. (1987): Studies on macromolecular components of human glomerular basement membrane and alterations in diabetes. Diabetes, 36: 374-381.

Snedecor, G. and Cochran, W. (1989): Cox D. Statistical Methods (8th edition). The Iowa State University Press.

Tapsell, L.C.; Hemphill, I.; Cobiac, L.; Patch, C.S.; Sullivan, D.R.; Fenech, M.; Roodenrys, S.; Keogh, J.B.; Clifton, P.M.; Williams, P.G.; Fazio, V.A. and Inge, K.E. (2006): Health benefits of herbs and spices: the past, the present, the future. Med. J. Aust. 185 (Suppl. 4), S4-S24.

Wang, W.H. and Wang, Z.M. (2005): Studies of commonly used traditional medicine-ginger. Zhongguo Zhong Yao Za Zhi. 30: 1569-1573.

Wilson, GL.; Hartig, PC.; Patton, NJ. and LeDoux, SP. (1988): Mechanisms of nitrosourea-induced beta-cell damage. Activation of poly (ADP-ribose) synthetase and cellular distribution. Diabetes. 37(2): 213-6.

Yemitan, O.K. and Izegbu, M.C. (2006): Protective effects of Zingiber offcinale (Zingiberaceae) against carbon tetrachloride and acetaminophen induced hepatotoxicity in rats. Phytother. Res. 20: 997-1002. 
Assiut Vet. Med. J. Vol. 58 No. 132 January 2012 